\title{
Covid-19 Salgın Sürecinde Hava Kalitesi Tahmini: Zonguldak Örneği
}

\author{
Büşra Duygu ÇELIK* a (D), Nursal ARICI ${ }^{a}$ (D) \\ a,* Gazi Üniversitesi Uygulamalı Bilimler Fakültesi Yönetim Bilişim Sistemleri Bölümü, 06010, Ankara, Türkiye
}

\begin{tabular}{l} 
MAKALE \\
BİLGISI \\
\hline Alınma: 07.06 .2021 \\
Kabul: 13.08 .2021 \\
\hline \\
Anahtar Kelimeler: \\
Covid-19,hava \\
kirliliği,hava kalitesi \\
tahmini,makine \\
öğrenmesi
\end{tabular}

ÖZ

Hava kirleticilerinin insan sağlığı üzerinde basit etkilerden erken ölüme kadar ciddi etkilere neden olduğu bilinmektedir. Özellikle solunum problemleri, akciğer rahatsızlkkları ve zatürre gibi birçok rahatsızlı̆a sebep olmaktadır. 30 Aralık 2019 itibariyle dünyayı etkisi altına alan Covid-19 salgın bir solunum yolu hastalğı̆dır ve hava yoluyla bulaşmaktadır. Günümüzde devam eden salgın sürecinde hava kalitesinin tahmin edilmesi ve buna yönelik tedbirlerin alınması Covid-19 gibi hava yoluyla bulaşan hastalıkların yayılma hızını etkilemesi açısından önem taşımaktadır. Çalışma, Covid-19 salgını öncesi ve Covid-19 salgın sürecinde ölçülen çeşitli kirletici konsantrasyonlarını ele alarak makine öğrenmesi yöntemleriyle hava kalitesini tahmin etmektedir. Çalışmada kullanılan veri seti, hava kirliliğinin yüksek olduğu, gelişmiş sanayiye sahip Zonguldak iline ait kirletici konsantrasyonlarından oluşmaktadır. Veriler, Çevre ve Şehircilik Bakanlığı (ÇSB) Hava İzleme İstasyonları web sitesinden sağlanmıştır. Tahmin başarısı yüksek beş farklı makine öğrenmesi yöntemi kullanılmıştır. Çalışma sonucunda en iyi başarı 0.016 (2019 veri seti) ve 0.021 (2020 veri seti) RMSE değerleri ile Karar Ağacı algoritmasında elde edilmiştir. Çalışmada Naive Bayes algoritması en düşük başarıya sahiptir. Deneysel sonuçlar, önerilen modelin hava kalitesini tespit etmek için verimli bir şekilde kullanılabileceğini göstermektedir.

https://dx.doi.org/10.30855/gmbd.2021.03.05

\section{Air Quality Forecast in the Covid-19 Outbreak Process: Zonguldak Case}

\section{ARTICLE INFO}

Received: 07.06 .2021 Accepted: 13.08.2021

Keywords:
Covid-19,air
pollution,air quality
prediction,machine
learning

\begin{abstract}
Air pollutants are known to cause severe effects on human health, from simple effects to premature death. It causes many ailments, especially respiratory problems, lung diseases, and pneumonia. As of December 30, 2019, the covid-19 outbreak affecting the world is a respiratory disease and is transmitted by air. In the current epidemic process, it is essential to predict air quality and take measures to affect the rate of spread of air-borne diseases such as Covid-19. The study predicts air quality through machine learning methods, considering the various concentrations of pollutants measured before the covid-19 outbreak and during the covid-19 outbreak. The data set used in the study consists of the pollutant concentrations of Zonguldak province, which has high air pollution and developed industry. The data was obtained from the Ministry of Environment and Urban Planning (MoLS) weather monitoring stations website. Five different machine learning methods with high predictive success were used. As a result of the study, the best hit was achieved in the decision tree algorithm with Rmse values of 0.016 (2019 dataset) and 0.021 (2020 dataset). The Naive Bayesian algorithm has the lowest success in the study. Experimental results suggest that the proposed model could be used efficiently to detect air quality.
\end{abstract}

https://dx.doi.org/10.30855/gmbd.2021.03.05

\footnotetext{
*Sorumlu yazar: nursal@gazi.edu.tr
}

To cite this article: B.D Çelik ve N. Arıcı, "Air Quality Forecast in the Covid-19 Outbreak Process: Zonguldak Case”, Gazi Journal of Engineering Sciences, vol.7, no.3, pp. 222-232, 2021. doi:10.30855/gmbd.2021.03.05 


\section{GIRISŞ (INTRODUCTION)}

Bu Hava kirliliği; atmosferdeki gaz, su buharı, duman, toz şeklindeki kirleticilerin, bütün canlılara zarar verecek seviyeye erişmesidir [1]. Özellikle sanayinin gelişmiş olduğu bölgelerde, hava kirliliği yaşam kalitesi için önemli bir etkendir. Hızla büyüyerek gelişen sanayi, çoğalan nüfus ve bunların sonucunda artan kentleşme hava kirliliğini arttırmıştır. Havada bulunan kirleticiler astım, zatürre, kalp krizi, bronşit ve diğer solunum problemleri gibi kronik hastalıkları tetikler veya kötüleştirir [2].

2019 yılının aralık ayında Çin'in Wuhan şehrinde ilk defa görülen Covid-19 vakasindan sonra dünyaya yayılan salgının Türkiye'deki ilk vakası 11 Mart'ta tespit edilmiştir. Covid-19 tespit edilen vakada en s1k solunum problemleri, akciğerlerde yoğun hasar ve hastalı̆̆ın ilerlemesi durumunda zatürre görülmektedir. Ayrıca kronik rahatsızlı̆̆ olan vakalarda kalp krizi ve ölüm riski daha da artmaktadır. Bilim insanları hava kalitesinin düşük olduğu bölgelerde yaşayan insanlarda Covid-19 vakalarının hastalı̆̆ 1 daha şiddetli geçirip geçirmeyeceğini araştırmaya başlamışlardır [3]. Hava kirliliği yoğun olan bölgelerde yaşayanların diğer insanlara göre hastalanmaya daha müsait olduğunu ve kirletici partiküllerin virüsün bulaşmasında kolaylaştırıcı etkiye sahip olduğunu belirtmişlerdir [4] .Ayrıca, hava kirliğinin yüksek olduğu şehirlerde Covid-19 vakalarının olması durumunda alınan önlemlerin arttırılması gerektiği, aksi taktirde yüksek ölüm oranları ile karşılaşılabileceği bildirilmiştir [3]. Ülkemizde alınan pandemi tedbirleri kapsamında 4 Nisan 2020'den itibaren otuz büyük şehir ve Zonguldak'a seyahat ve sokağa çıkma kısıtlamasına başlanmıştır. Zonguldak büyük şehir olmamakla birlikte kısıtlama kapsamına alınmasının nedeni hava kirliliğinin en yoğun olduğu bölgelerden biri olup vaka sayısı bakımından da riskli grubunda yer almasıdır. Bu gerekçeyle çalışmamızda Zonguldak ili hava kalitesi değerlendirilmesi ele alınmıştır.

$\mathrm{Bu}$ çalışmanın amacı, Zonguldak ilindeki Covid-19 salgını öncesi ve esnasındaki hava kalitesi değişimlerini incelemek ve bu amaç doğrultusunda kirletici parametreleri makine öğrenmesi yöntemleriyle tahmin etmektir. Zonguldak ilinde gözlemlenen $\mathrm{PM}_{10}, \mathrm{SO}_{2}, \mathrm{NO}_{2}, \mathrm{O}_{3}$ ve $\mathrm{CO}$ hava kirleticilerinin konsantrasyonları alınarak [5] salgın öncesi ve salgın süreci olmak üzere iki ayrı veri seti oluşturulmuştur. $\mathrm{Bu}$ veri setleri üzerinde tahmin başarısı yüksek olan Destek Vektör Makinesi (SVM), K-En Yakın Komşu (KNN), Karar Ağacı (DT), Rastgele Orman (RF), ve Naive Bayes (NB) makine öğrenmesi algoritmaları uygulanmıştır. Çalışmada kullanılan verileri bölme işleminde öncelikle $\% 80$ eğitim ve $\% 20$ test, ardından $\% 70$ eğitim ve $\% 30$ test verisi alınarak model ayrı ayrı denenmiştir. En son aşırı öğrenmeyi engellemek ve daha yüksek başarı için $\% 67$ 'si eğitim ve \%33'ü test verisi olarak kullanılmıştır. Her bir yöntemin tahmin başarı performansı doğruluk, RMSE ve $\mathrm{R}^{2}$ kriterlerine göre kıyaslanmıştır. Çalışmanın sonraki bölümleri şu şekilde yapılandırılmıştır.

İkinci bölümünde, literatürdeki Covid-19 salgını ile hava kirliliği arasındaki ilişkiyi ve hava kalitesi tahmini için kullanılan makine öğrenmesi yöntemlerini konu alan çalışmalar incelenmiştir. Üçüncü bölümde çalışmada kullanılan veri seti ile tahminleme modelinde kullanılan makine öğrenmesi yöntemleri hakkında bilgi verilmiştir. Dördüncü bölümde Covid-19 öncesi ve Covid-19 sürecindeki veriler değerlendirilmiş ve uygulanan modelin doğruluk değerleri karşılaştırılmıştır. Son bölümde ise, tahminleme sonucu elde edilen çıktılar yorumlanmıştır.

\section{2.ÖNCEKİ ÇALIŞMALAR (PREVIOUS STUDIES)}

İnsan sağlığını ciddi anlamda tehdit eden ve birçok hükümeti önlem alamaya iten Covid-19 salgını, bulaştığı kişilerde bağışıklık sisteminin zayıf olması durumunda kişi, hastalığı daha ağır atlatabilmektedir. Hava kalitesinin düşük olması kişilerde bağışıklık sisteminin zayıflatacak birçok hastalığa neden olabilmektedir. Bu yüzden birçok araştırmacı, hava kalitesini tahmin edebilmek amaciyla yaptıkları çalışmaların yanında Covid-19'un hava kalitesiyle ilişkisini de incelemektedirler.

Zhu ve ark., Çin'de bulunan 120 şehirdeki $\mathrm{PM}_{10}$, $\mathrm{PM}_{2.5}, \mathrm{SO}_{2}, \mathrm{CO}, \mathrm{NO}_{2}$ ve $\mathrm{O}_{3}$ hava kirletici parametreleri ile günlük tespit edilen Covid-19 vakalarını değerlendirmeye almış ve bu veriler üzerinde genelleştirilmiş katkı modeli uygulayarak Covid-19 ile hava kirliliğgi arasındaki ilişkiyi araştırmışlardır. $\mathrm{Bu}$ çalışmanın sonucunda hava kirliliği ve Covid-19 salgını arasında anlamlı pozitif güçlü bir ilişki olduğu saptanmıştır [6].

Rodríguez-Urrego ve Rodríguez-Urrego, karantina başlangıcından önce ve sonra ölçülen, Dünya Sağlık Örgütü'ne göre dünyanın en kirli 50 başkentindeki $\mathrm{PM}_{2.5}$ partikül maddesinin emisyon davranışını ele almış ve Covid-19 sürecinde hava kalitesi incelemiştir. Çalışmanın sonucuna göre karantina boyunca çoğu şehrin kirletici konsantrasyonlarında ciddi bir düşüş olduğu görülmüştür. Ayrıca seçilen 
şehirlerden çoğunun hava kalitesi olumlu etkilenmiştir [7].

Başka bir çalışmada Brandt ve arkadaşları, Covid19 ölümleri üzerinde hava kirliliğinin etkisini incelemişler ve nüfus yoğunluğunun yüksek olduğu yerleşim yerlerinde hava kirliliğinin daha yoğun olduğunu ve bu yerlerdeki hava kirliliğinin Covid-19 ölümlerinin üzerinde etkili olduğunu vurgulamıştır [8].

Hava kalitesinin değişimini izleme, tahmin etme ve gerekli tedbirlerin erken alınması konuları Covid-19 salgın sürecinde daha da önem taşımaktadır. Özellikle hava kalitesinin doğru tahmin edilmesi, ekolojik denge ve insan sağlığı üzerinde önemli bir rol oynamaktadır. Son yıllarda araştırmacılar klasik istatistik yöntemlerin dışında tahmin başarısı yüksek olan makine öğrenmesi yöntemleri ile hava kalitesini tahmin etmeye çalışmışlardır.

Doreswamy ve arkadaşları, havadaki $\mathrm{PM}_{10}$ ve $\mathrm{PM}_{2.5}$ konsantrasyonunu tahmin etmeye yönelik makine öğrenmesi tahmin modellerini kullanmış ve bu modelleri mevcut geleneksel modellerle karşılaştırılmıştır. Elde ettikleri $0,9336 \mathrm{R}^{2}$ ve 0.1302 RMSE performans değerleriyle, makine öğrenmesi modelleri tahmin performansinda geleneksel modellere göre daha iyi performans göstermiştir [9].

Başka bir çalışmada Kang ve arkadaşları, Çin'in Shenzhen şehrinden alınan veriler kullanılarak hava kalitesi haritası görselleştirilmiştir. Ayrıca Yapay Sinir Ağı, Genetik Algoritma, Rastgele Orman, Karar Ağacı, Derin İnanç Ağı(Deep Belief Network) ve Destek Vektör Makinesi kullanılan çalışmalarda oluşturulan modellerin çeşitli avantajları ve dezavantajları anlatılmıştır. Karşılaştırılan çalışmalardan en başarılı olan Karar Ağacı Algoritmas1, \%89,46 doğruluk oranına sahiptir [10].

Masood ve arkadaşları, 2016-2018 arasındaki iki yıllık döneme karşılık gelen çeşitli meteorolojik ve kirletici parametrelerin girdileri üzerine SVM ve YSA gibi farklı modeller oluşturulmuştur. $\mathrm{PM}_{2.5}$ tahmini için modellerin performans değerlendirmesi yapılmış ve sonuçlar tartışılmıştır. YSA ve SVM için ortalama hata karesi değerleri sirasıyla 0.0191 ve 0.0314 bulunmuştur [11].

Deters ve arkadaşları, araştırma makalelerinde ince partikül madde veya $\mathrm{PM}_{2.5}$ nedeniyle milyonlarca erken ölüme neden olan diş mekân kirliliği araştırmasını önermişlerdir. $\mathrm{PM}_{2.5}$ konsantrasyonunu tahmin etmek için altı yıllık meteorolojik ve kirlilik veri analizine dayalı bir makine öğrenmesi yaklaşımı geliştirmişlerdir [12].

Bali çalışmasında, Hindistan hava kalitesinin tahmin ve analizini makine öğrenmesi algoritmalarından SVM, RF, NB kullanarak modellemiştir. En yüksek başarıyı \%99,1 ile rastgele orman algoritmasında elde etmiştir [13].

\section{MATERYAL VE YÖNTEM (MATERIAL AND METHOD)}

\subsection{Zonguldak İli Hava Kalitesi (Air Quality of Zonguldak City)}

Son yıllarda hava kalitesi oldukça kötüleşen illerimizden biri de Zonguldak'tır [5]. Türkiye Çevre Sorunları ve Öncelikleri Envanteri Değerlendirme Raporu'nda Zonguldak ilinin en önemli çevre sorununun hava kirliliği olduğu belirtilmiştir. Ayrıca Zonguldak, Türkiye İstatistik Kurumu'nun Çevre İstatistiklerine bakıldığında partikül madde kirliliği bakımından Türkiye'nin havası en kirli şehirleri arasındadır [14]. Zonguldak'ta hava kirliliğine neden olan başlıca kirleticiler genellikle sanayileşme, soğuk havadaki evsel ısınma ve trafik kaynaklıdır. Özellikle sanayileşmenin oldukça yoğun olduğu Batı Karadeniz bölgesinde bulunan ilimiz, taş kömürü madenciliği, enerji ve metalürji sektörü sanayisinin büyük bir bölümünü oluşturmaktadır. Enerji sektöründe yer alan Çatalağzı Termik Santrali ülkemizdeki ilk termik santral olup katı yakıt olarak taş kömürü kullanmaktadır [5].

Zonguldak'ta görülen hava kirleticiler partiküller ve gazlar şeklinde iki alt gruba ayrılır. Partikül maddelerden $\mathrm{PM}_{10}$, çoğunlukla fabrika faaliyetleri, inşaatlar, trafik, termik santraller ve evsel isınma kaynaklıdır. Hava yoluyla taşınan bu kirletici türü öncelikle astım gibi solunum rahatsılıkları, kalp damar hastalıkları, akciğer rahatsızlıklarına sebep olarak erken ölüm riski taşımaktadır.PM $\mathrm{M}_{10}$ 'nun yanı sıra izleme istasyonunda ölçülen hava kirletici parametreleri kısaca açıklanmıştır [15]:

Renksiz, yanıcı olmayan ve gaz halde bulunan kükürt dioksit $\left(\mathrm{SO}_{2}\right)$, genellikle 1sınma, endüstriyel faaliyetler ve trafik bölgelerinde oluşan bir kirletici türüdür. Diğer kirleticilerle birleştiğinde damlalar veya katı partiküller halinde uzun mesafeler taşınabilir. Uzun süre maruz kalınması halinde solunum yolu rahatsızlıklarına, kalp krizi riskinin artmasına neden olmaktadır [15].

Azot oksit $\left(\mathrm{NO}_{\mathrm{X}}\right)$ emisyonları insanların sağlı̆̆ üzerinde yarattığı etki bakımından en zararlı kirletici 
olup trafik ve endüstriyel tesisler başlıca kaynağıdır. Kısa süre maruz kalındığında bile solunum sistemi üzerinde ağır hasarlara yol açan $\mathrm{NO}_{\mathrm{X}}$ emisyonları kronik hastalarda daha da büyük tahribatlara sebep olmaktadır. Uzun süreli maruz kalınması halinde ise bölgedeki solunum yolu rahatsızlıklarının arttığı gözlemlenmiştir [15].

Karbon monoksit (CO) gazı tam yanmamış olan yakıtlar sonucu ortaya çıkan kokusuz ve renksiz bir gazdır. Kış mevsiminde en yüksek değere ulaşan CO' in ana kaynağı trafikte oluşan egzoz gazları ve sigara dumanıdır. Kandaki hemoglobine bağlanarak hücrelere giden oksijen miktarının azalmasına sebep olur. CO gazına maruz kalan insanlarda kalp ve solunum rahatsılıkları görülebilir [15].

Ozon $\left(\mathrm{O}_{3}\right)$, doğrudan ortam havasına karışmayan, renksiz ve kokusuz bir gaz olup karmaşık kimyasal tepkimeler sonucunda oluşur. Maruz kalma süresine göre tahribat oranı artar ve en yüksek risk grubu çocuklar ve kronik hastalardır [15].

\subsection{Veri Seti (Dataset)}

Veri seti, Çevre ve Şehircilik Bakanlığı (ÇŞB) Hava İzleme İstasyonları web sitesinden sağlanmıştır [16]. Bu web sitesinde Türkiye'deki tüm illerin çeşitli bölgelerinden $7 \times 24$ ölçülen $\mathrm{SO}_{2}, \mathrm{NO}_{2}, \mathrm{NO}_{\mathrm{X}}, \mathrm{CO}, \mathrm{O}_{3}$, $\mathrm{PM}_{10}$ ve $\mathrm{PM}_{2,5}$ kirletici parametrelere ait veri setleri yayımlanmaktadır. Bu çalışmada veriler, Zonguldak ili Çatalağzı beldesinde yer alan hava izleme istasyonundan alınmıştır (Şekil 1).

Termik santralin yer aldığı Çatalağzı-Kuzyaka izleme istasyonundan, salgın öncesi 01.01.201931.12.2019 ve salgın sürecine ait 11.03.2020-
31.12.2020 tarih aralığına ait yapılan ölçüm verileri alınmıştır. Çalışmada kullanılan veri seti, 15.578 veriden oluşmaktadır. 8.737 veri 2019 yılına, 6841 veri de 2020 yılına aittir. Türkiye'de resmi kayıtlarda salgın başlangıcı mart ayı kabul edildiğinden 2020 yılına ait ocak ve şubat ayları değerlendirmeye dahil edilmemiştir. Seçilen istasyonda $\mathrm{SO}_{2}, \mathrm{NO}_{2}, \mathrm{O}_{3}, \mathrm{CO}$ ve $\mathrm{PM}_{10}$ kirletici parametreleri ölçülmektedir.

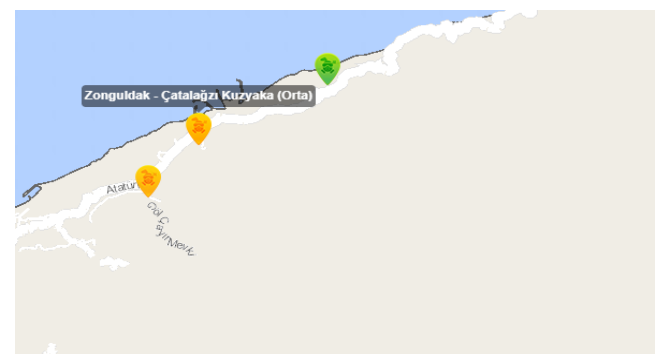

Şekil 1. Zonguldak-Çatalağzı Kuzyaka Hava İzleme İstasyonu (Zonguldak-Çatalağzı Kuzyaka Weather Monitoring Station)

Çalışmada tahmin edilmek istenen bağımlı değişken Hava Kalite İndeksi (HKI), çevremizdeki hava kalitesinin sağlımız üzerindeki etkisinin ne olduğunu anlamamıza yarayan ölçektir. Bu indeks, havadaki kirleticilerin konsantrasyonlarına göre hava kalitesini iyi, orta, hassas, sağlıksız, kötü ve tehlikeli olmak üzere beş farklı seviyede ortaya koymaktadır. Ulusal Hava Kalite İndeksi kesme noktaları Tablo 1 'de verilmiştir. Ayrıca hava kirliliğine karşı hassas olan insanların sağlıklarını korumaya yardımcı olan bir faktördür. HKİ, çevresel faktörlerin insan sağlığına hangi oranda etki yaptığını göstererek, sağlık açısından tehdit oluşturan durumları önlemek için kullanılmaktadır.

Tablo 1. Ulusal hava kalite indeksi kesme noktaları(National air quality index breakpoints) [5]

\begin{tabular}{|c|c|c|c|c|c|c|}
\hline \multirow{2}{*}{ İndeks } & \multirow{2}{*}{ HKİ } & $\mathrm{SO}_{2}\left[\mu \mathrm{g} / \mathrm{m}^{3}\right]$ & $\mathrm{NO}_{2}\left[\mu \mathrm{g} / \mathrm{m}^{3}\right]$ & $\mathrm{CO}\left[\mu \mathrm{g} / \mathrm{m}^{3}\right]$ & $\mathrm{O}_{3}\left[\mu \mathrm{g} / \mathrm{m}^{3}\right]$ & $\mathrm{PM}_{10}\left[\mu \mathrm{g} / \mathrm{m}^{3}\right]$ \\
\hline & & $1 \mathrm{Sa}$. Ort. & $1 \mathrm{Sa}$. Ort. & $8 \mathrm{Sa}$. Ort. & $8 \mathrm{Sa}$. Ort. & $24 \mathrm{Sa}$. Ort. \\
\hline İyi & $0-50$ & $0-100$ & $0-100$ & $0-5500$ & $0-120$ & $0-50$ \\
\hline Orta & $51-100$ & $101-250$ & $101-200$ & $5501-10000$ & $121-160$ & $51-100$ \\
\hline Hassas & $101-150$ & $251-500$ & $201-500$ & $10001-16000$ & $161-180$ & $101-260$ \\
\hline Sağlıksız & $151-200$ & $501-850$ & $501-1000$ & $16001-24000$ & $181-240$ & $261-400$ \\
\hline Kötü & $201-300$ & $851-1100$ & $1001-2000$ & $24001-32000$ & $241-700$ & $401-520$ \\
\hline Tehlikeli & $301-500$ & $>1101$ & $>2001$ & $>32001$ & $>701$ & $>521$ \\
\hline
\end{tabular}

Çalışmamızda hava kirliliği parametreleri $\mathrm{SO}_{2}$, $\mathrm{NO}_{2}, \mathrm{CO}, \mathrm{O}_{3}, \mathrm{PM}_{10}(\mu \mathrm{g} / \mathrm{m} 3)$ giriş parametreleri olarak ele alınmıştır ve bağımlı değişken olan HKİ değeri tahmin edilmiştir. Veri önişleme aşamasında, öncelikle aykırı değerler tespit edilerek yerine ortalama değer atanmıştır. Ardından eksik veriler tespit edilmiştir. 2020 yılı temmuz ayına ait ölçümlerde veri bulunmadığından temmuz ayı değerlendirmeye dahil edilmemiştir. Eksik veri olan diğer aylarda kirleticilerin ortalama değerleri kullanılarak tamamlanmıştır. Bir sonraki aşamada verilerin ortak bir ölçekte değerlendirilebilmesi için (1) nolu eşitlikteki min-max normalizasyonu kullanılmıştır. 


$$
x^{\prime}=\frac{x_{i}-x_{\min }}{x_{\max }-x_{\min }}
$$

$x^{\prime}=$ Normalize edilmiş veri

$x_{i}=$ Girdi değeri

$x_{\min }=$ Girdi seti içerisinde yer alan en küçük sayı

$x_{\max }=$ Girdi seti içerisinde yer alan en büyük sayı

Normalize edilen veriler günlük olarak kıyaslandığında en yüksek ölçülen değer 'max' değeri ile belirtilmiştir. 'max' değeri ölçüm yapılan günün HKI' sine eşittir. HKİ değeri için 1'den 6'ya kadar 'Durum' etiketi oluşturulmuştur. İlgili etiketlerin değer aralıkları tablo 2'de verilmiştir.

Tablo 2. HKİ aralığına göre durum etiketi dağılımı (Status label distribution by AQI range)

\begin{tabular}{lll}
\hline İndeks & HKİ & Durum \\
\hline İyi & $0-50$ & 1 \\
Orta & $51-100$ & 2 \\
Hassas & $101-150$ & 3 \\
Sağl1ksız & $151-200$ & 4 \\
Kötü & $201-300$ & 5 \\
Tehlikeli & $301-500$ & 6 \\
\hline
\end{tabular}

Daha sonra normalize edilmiş parametreler kullanılarak korelasyon matrisi oluşturulmuş ve parametreler arasındaki ilişki incelenmiştir. Şekil 2'de havayı kirleten ve veri setinde yer alan parametreler ile hava kalitesi arasındaki ilişki güçleri $[0.0,1.0]$ aralığında gösterilmiştir. Şekil incelendiğinde $\mathrm{PM}_{10}$ parametresinin hava kalitesi indeksi ile 0.93'lük pozitif güçlü bir korelasyona sahip olduğu görülmektedir. Hava Kalite İndeksi ile $\mathrm{PM}_{10}$ haricindeki diğer parametreler arasındaki ilişki güçleri sirasiyla $\mathrm{NO}_{2}, \mathrm{SO}_{2}, \mathrm{CO}$ ve $\mathrm{O}_{3}$ 'a aittir.

2019-2020 günlük ölçümlenen kirletici konsantrasyonlarından oluşan veri seti incelendiğinde $\mathrm{PM}_{10}$ ve Hava Kalite İndeksi arasındaki ilişki Şekil 3 ve Şekil 4'teki gibidir. Grafiklerde görüldüğü üzere $\mathrm{PM}_{10}$ artış azalış eğrisi hava kalite eğrisi ile birçok noktada paralellik göstermektedir. Bundan dolayı $\mathrm{PM}_{10}$ parametresiyle hava kalitesi arasında pozitif güçlü bir ilişki olduğu çıkarımı yapılabilir.

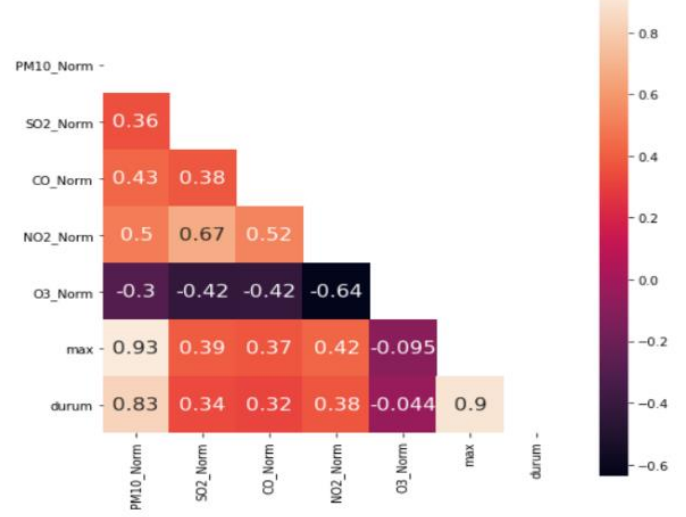

Şekil 2. Hava Kirleticilerin Korelasyon Matrisi (Correlation Matrix of Air Pollutants)

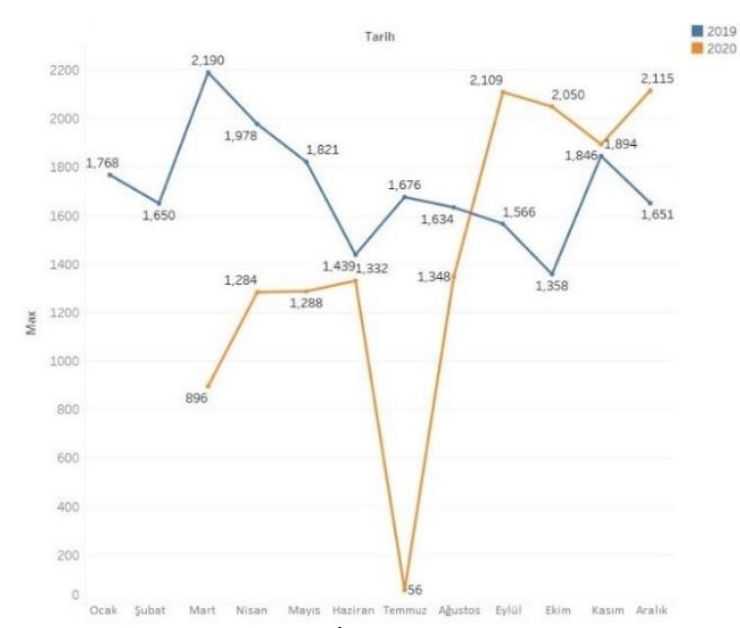

Şekil 3. HKİ artış azalış eğrisi

(AQI increase and decrease curve)

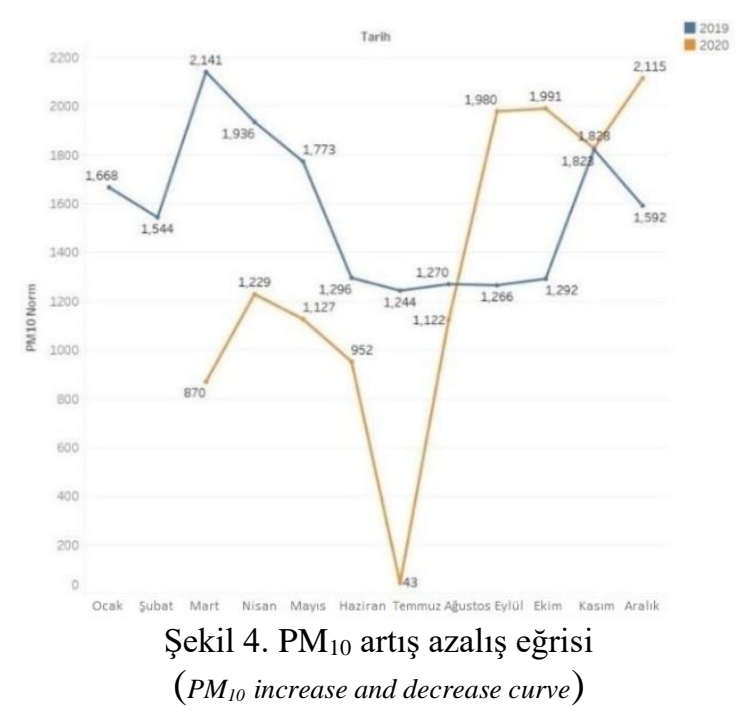

Covid-19 salgını öncesi ve süresince ölçülen kirletici konsantrasyonlarının aylık dağılımı Şekil 5 ve Şekil 6'da görselleştirilip kıyaslanmıştır. Çalışmada 
2020 yılına ait salgın süreci ele alındığından Ocak ve Şubat ayları değerlendirmeye dahil edilmemiştir.

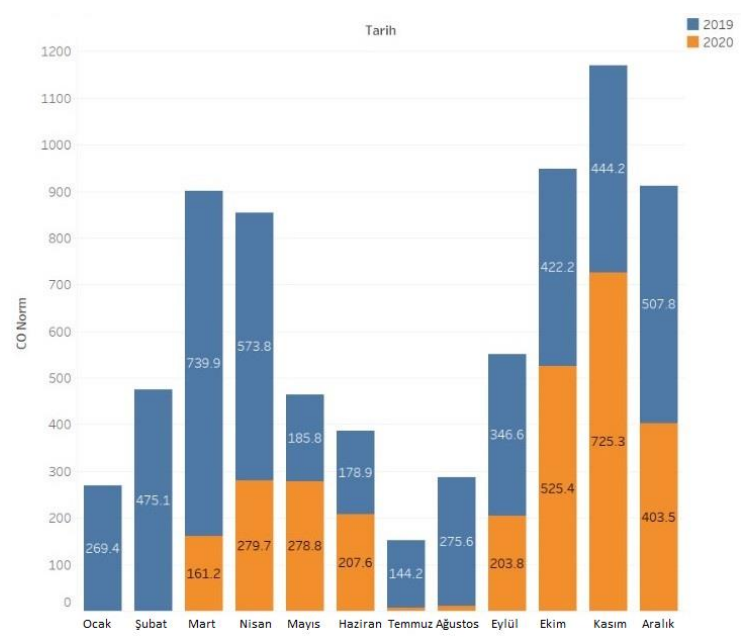

Şekil 5. CO Parametresinin Yıl Bazlı Dağılımı

(Year-Based Distribution of CO Parameter)

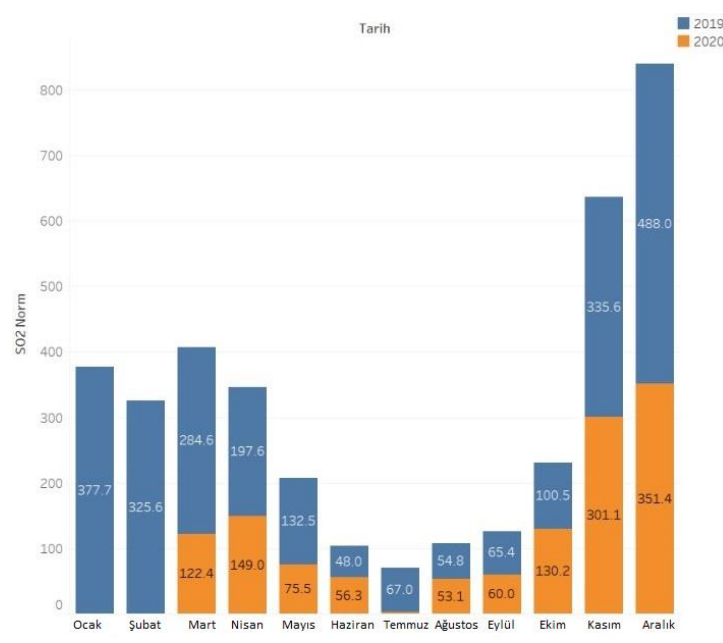

Şekil 6. SO2 Parametresinin Yıl Bazlı Dağılımı

(Year-Based Distribution of $\mathrm{SO}_{2}$ Parameter)

Şekil 5 ve Şekil 6'daki grafikler incelendiğinde, Mart ayında başlayan karantina ile $\mathrm{CO}$ ve $\mathrm{SO}_{2}$ kirleticilerinin ölçümlenen değerlerinde ciddi bir düşüş görülmektedir ve bu düşüşler DSÖ’nün çalışmalarıyla da desteklenmektedir [17][18].

Şekil 7 ve Şekil 8'de PM10 ve NO2 hava kirletici parametrelerinin yıllara göre dağılımları görselleştirilmiştir. $\mathrm{Bu}$ grafiklerde de $\mathrm{CO}$ ve $\mathrm{SO}_{3}$ parametrelerinde görüldüğü gibi 2020 yılında ciddi düşüşler görülmektedir.

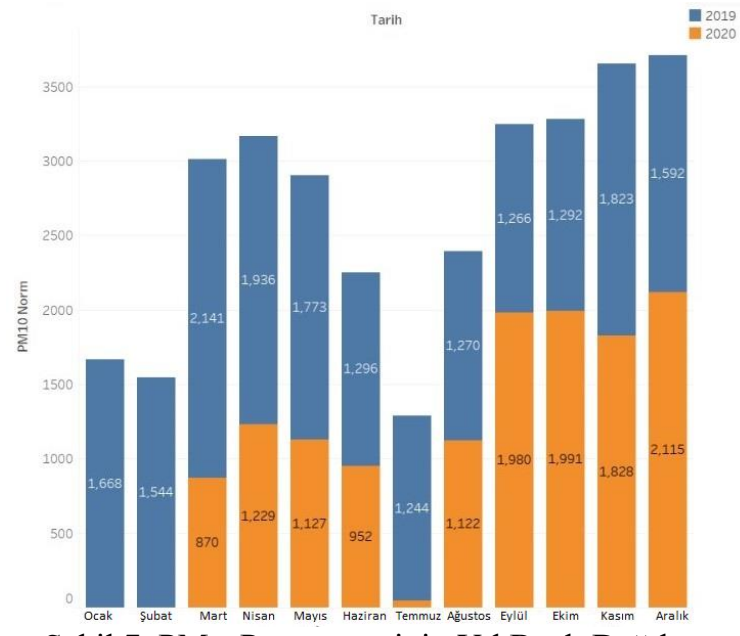

Şekil 7. $\mathrm{PM}_{10}$ Parametresinin Yıl Bazlı Dağılımı

(Year-Based Distribution of $P M_{10}$ Parameter)

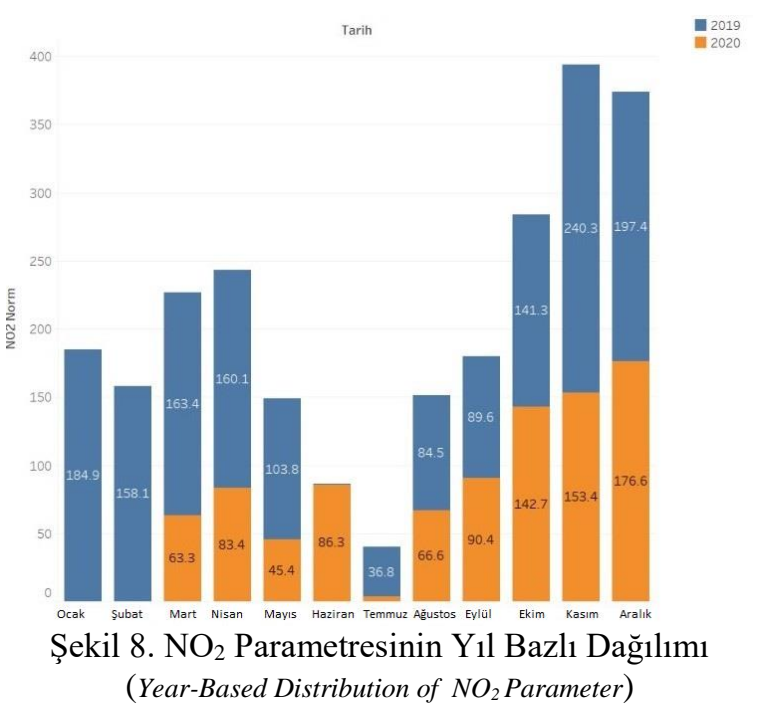

Son olarak Şekil 9'da $\mathrm{O}_{3}$ hava kirletici parametresi yıllara göre dağılımı görselleştirilmiştir. Şekilde görüldüğü üzere $\mathrm{O}_{3}$ hava kirletici parametresinde de düşüş olduğu gözlemlenmiş fakat düşüşün önceki dört parametrede olduğu kadar kesin olmadığ görülmektedir. Karantina sürecinde genel olarak tüm kirletici parametrelerde azalma tespit edilmiştir. Ayrıca haziran ayında tekrar normalleşme sürecine girilmesi ile kirletici konsantrasyonlarının arttığ görülmektedir. 


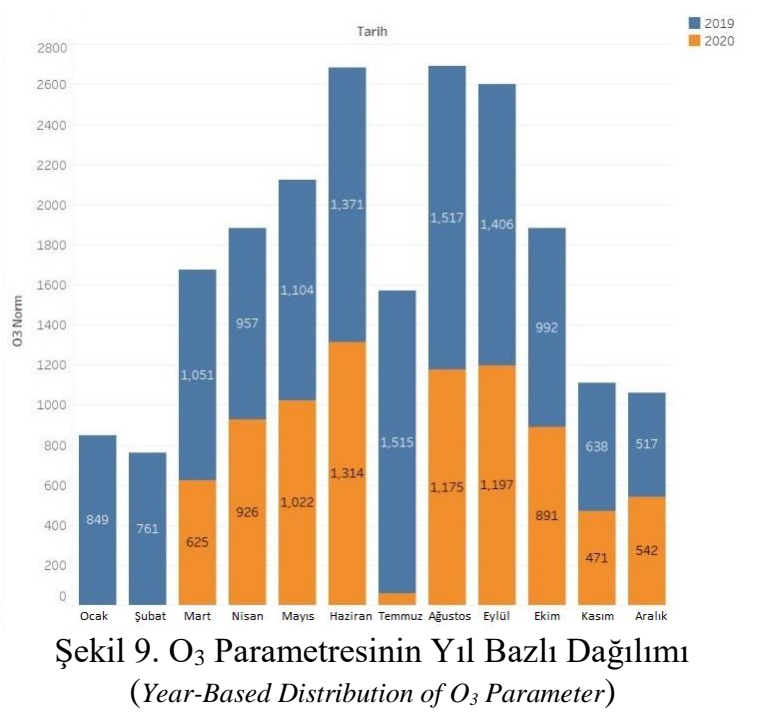

Modelin kurulması ve değerlendirilmesi aşamasında Python temelli bir kütüphane olan Scikitlearn kütüphanesi kullanılmıştır. Makine öğrenmesi yöntemlerinden KNN, SVM, RF, KA ve NB ile hava kalitesi modellenmiş ve başarı oranları karşılaştırılmıştır.

\subsection{Makine Öğrenmesi Algoritmaları (Machine Learning Algorithms)}

Günümüzde gelişen teknolojiyle beraber verinin elle işlenmesi ve analizinin yapılması daha zor hale gelmiştir. Yapısal olarak öğrenebilen yapay zekâ algoritmalarının bir alt alanı olan makine öğrenmesinin temel amacı veriler üzerinde başarılı tahminler elde etmektir. Makine öğrenmesi algoritmalarıyla hava kalitesi tahmin sistemi için kullanılan algoritmanın seçimi çok önemlidir. Yapılan sistematik inceleme, 2017'den bu yana, atmosfer kirliliğini tahmin etmek için makine öğrenmesi tekniklerinin uygulanmasının önemli ölçüde arttığını ortaya koymaktadır [19]. Çalışmada, başarı oranlarının yüksek olması sebebiyle kullanılan makine öğrenmesi yöntemleri aşağıda açıklanmıştır. Ayrıca her yönteme ait 2019 ve 2020 yılları hata matrisleri ve doğruluk oranları da ek olarak verilmiştir.

\subsubsection{Destek vektör makinesi (Support Vector Machine- SVM)}

İki ve daha fazla boyuttaki verileri doğru, düzlem veya hiper düzlem yardımıyla birbirinden ayırarak sinıflandırma ve regresyon analizi yapan makine öğrenmesi algoritmasıdır. $\mathrm{Bu}$ algoritmanın amacı verilen veri noktalarını olabildiğince en iyi şekilde ayırmaktır. Küçük ve orta ölçekli verilerde daha başarılı olduğu gözlemlenen SVM algoritması, hafızayı verimli kılan karar fonksiyonunda eğitim noktalarının alt kümesini kullanır [20]. 2019 ve 2020 yıllarına ait veri setlerine uygulanan SVM algoritması sonucunda elde edilen hata matrisleri Şekil 10 ve Şekil 11' de verilmiştir.

\begin{tabular}{|c|c|c|c|c|c|}
\hline$[[1202$ & 13 & 0 & 0 & 0 & 0] \\
\hline 6 & 1432 & 3 & 0 & 0 & 0] \\
\hline$\theta$ & 1 & 189 & 0 & 0 & 0] \\
\hline$\theta$ & 0 & 8 & 19 & 2 & 0] \\
\hline 0 & 0 & 0 & 0 & 8 & 0] \\
\hline$\theta$ & 0 & 0 & 0 & 0 & 1]] \\
\hline \multicolumn{6}{|c|}{ Support-Vector-Machine Accuracy 0.9885575589459085} \\
\hline \multicolumn{6}{|c|}{ Support-Vector-Machine Rmse: 0.1069693463291776} \\
\hline upport & & or $-M_{\dot{z}}$ & hine & R2: & .9746791055795522 \\
\hline
\end{tabular}

Şekil 10. 2019 hata matrisi (confusion matrix-2019)

\begin{tabular}{|c|c|c|c|c|c|}
\hline$[1286$ & 0 & 0 & 0 & 0 & 0] \\
\hline 23 & 802 & 2 & 0 & 0 & 0] \\
\hline 0 & 4 & 106 & 0 & 0 & 0] \\
\hline 0 & 0 & 3 & 24 & 1 & 0] \\
\hline 0 & 0 & 0 & 1 & 5 & 0] \\
\hline 0 & 0 & 0 & 0 & 0 & 1] \\
\hline
\end{tabular}

Support-Vector-Machine Accuracy 0.9849424269264836 Support-Vector-Machine Rmse: 0.12270930312537998 Support-Vector-Machine R2: 0.9674352709627065

Şekil 11. 2020 hata matrisi (confusion matrix-2020)

\subsubsection{Rastgele orman (Random forest $-R F$ )}

Hem sinıflandırma hem de regresyon amaçlı kullanılabilen denetimli bir makine öğrenme algoritmasıdır. Genellikle sınıflandırma görevleri için tercih edilir. Birden çok karar ağacından oluşan Rastgele orman algoritması veri öğeleri üzerinde rastgele bir orman oluşturur ve her biri için tahmin yapar. En son olarak da aralarındaki en iyi çözümü seçer. $\mathrm{Bu}$ sayede Rastgele orman, sonuçların ortalamasını alarak aşırı öğrenmeyi azaltır ve birbirinden bağımsız parametrelerle farklı karar ağaçları üzerinden değerlendirmeye aldığı için başarısı oldukça yüksektir [20]. 2019 ve 2020 yıllarına ait veri setlerine uygulanan RF algoritması sonucunda elde edilen hata matrisleri Şekil 12 ve Şekil 13 ' te verilmiştir.

\begin{tabular}{|c|c|c|c|c|c|}
\hline \multirow{2}{*}{ 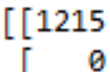 } & 0 & 0 & 0 & 0 & 0] \\
\hline & 1440 & 1 & 0 & 0 & 0] \\
\hline$\theta$ & $\theta$ & 190 & 0 & 0 & 0] \\
\hline$\theta$ & 0 & 5 & 24 & $\theta$ & 0] \\
\hline$\theta$ & 0 & 1 & $\theta$ & 7 & 0] \\
\hline 0 & 0 & 0 & 0 & 0 & 1]] \\
\hline \multicolumn{6}{|c|}{ Random-Forest Accuracy: } \\
\hline \multirow{2}{*}{\multicolumn{2}{|c|}{$\begin{array}{l}\text { Random-Forest } \\
\text { Random-Forest }\end{array}$}} & \multicolumn{4}{|c|}{0.0588846871438385} \\
\hline & & $\mathrm{R} 2$ : & 0.99 & 327 & 16907734 \\
\hline
\end{tabular}

Şekil 12. 2019 hata matrisi (confusion matrix-2019) 


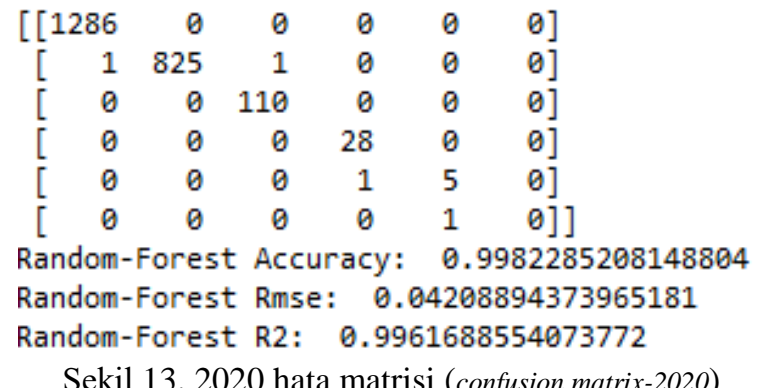

\subsubsection{K en yakın komşu (K-nearest neigbour)}

K En Yakın Komşu algoritması, sınıflandırma ve regresyon problemlerinin çözümünde kullanılan basit, oldukça yaygın ve denetlenen bir makine öğrenmesi algoritmasıdır. KNN algoritmasında ilk aşamada veriler etiketlenir ve etiketlenen bu verilerden bir eğitim kümesi hazırlanır. Ardından $\mathrm{k}$ adet sınıf merkezi tanımlandıktan sonra bir uzaklık fonksiyonu belirlenir. Daha önce karşılaşılmamış bir veri ile yüz yüze gelindiğinde belirlenen uzaklık algoritmas1 kullanılarak karşılaşılan verinin eğitim kümesindeki verilerle olan mesafesi ölçümlenir ve aralarında uzaklığ 1 en kısa olan $\mathrm{k}$ adet veri eğitim kümesinden seçilerek sınıflama kümesi oluşturulur. En son aşamada, seçilen yeni verinin sınıfı, sınıflama kümesinin en sık içerdiği sınıf olarak tanımlanır ve oluşturulan model sona erdirilir [21]. 2019 ve 2020 yıllarına ait veri setlerine uygulanan KNN algoritması sonucunda elde edilen hata matrisleri Şekil 14 ve Şekil 15 ' te verilmiştir.

\begin{tabular}{|c|c|c|c|c|c|c|}
\hline$[[11$ & 91 & 24 & 6 & 0 & 0 & 0] \\
\hline D & 19 & 1418 & 4 & 0 & 0 & 0] \\
\hline ] & 0 & 8 & 182 & $\theta$ & 0 & 0] \\
\hline & 0 & 0 & 8 & 21 & 0 & 0] \\
\hline L & 0 & 0 & 1 & 2 & 5 & 0] \\
\hline 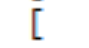 & 0 & $\theta$ & 0 & 0 & 1 & 0]] \\
\hline NN & \multicolumn{3}{|c|}{ Accuracy: } & \multicolumn{3}{|c|}{0.9767683772538142} \\
\hline KNN & \multicolumn{2}{|c|}{ Rmse: } & 9. 155 & 9423 & & 96 \\
\hline INN & R2: & : $\quad 0.9$ & 94628 & 9118 & 4137 & \\
\hline
\end{tabular}

Şekil 14. 2019 hata matrisi (confusion matrix-2019)

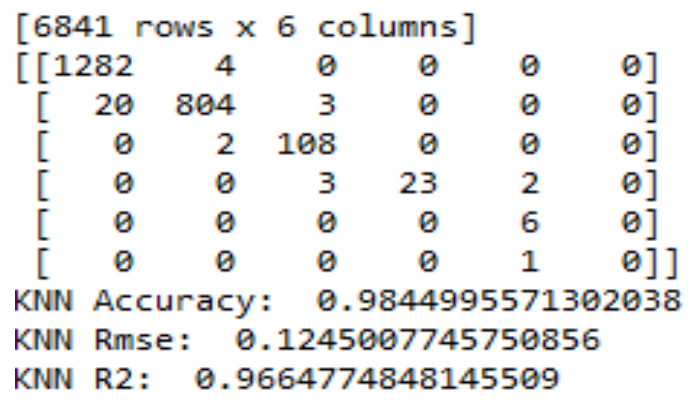

Şekil 15. 2020 hata matrisi (confusion matrix-2020)

\subsubsection{Karar ağacı (Decision tree-DT)}

Karar Ağacı algoritması, popüler ve en basit makine öğrenmesi algoritması olup bir ağaç yapısı türünde sinıflandırma ve regresyon modelleri oluşturur. Algoritmanın amacı, önceki eğitim verilerinden çıkarılan karar kurallarını öğrenerek nihai sonuç değişkeninin sınıfını tahmin etmek için bir model oluşturmaktır. Karar Ağacı, düğüm ve dallardan meydana gelmektedir. Her bir dügüum bir özelliği temsil etmektedir ve her dal ise bir kararı temsil etmektedir [22]. 2019 ve 2020 yıllarına ait veri setlerine uygulanan DT algoritması sonucunda elde edilen hata matrisleri Şekil 16 ve Şekil 17' de verilmiştir.

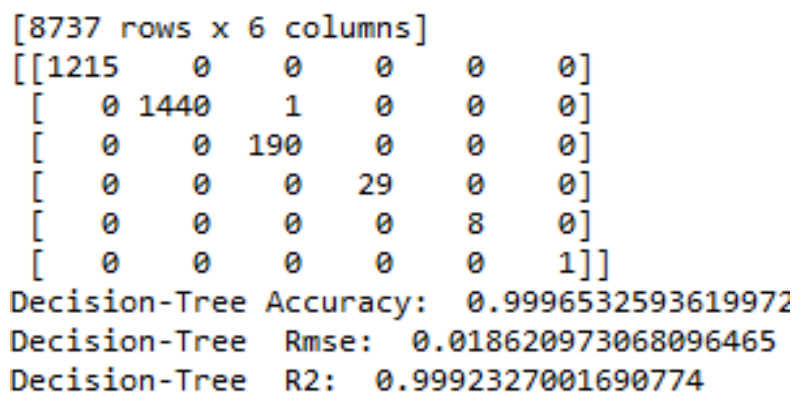

Şekil 16. 2019 hata matrisi (confusion matrix-2019)

\begin{tabular}{|c|c|c|c|c|c|}
\hline \multicolumn{6}{|c|}{$[6841$ rows $\times 6 \mathrm{cc}$} \\
\hline 0 & 826 & 1 & 0 & 0 & 0] \\
\hline 0 & 0 & 110 & 0 & 0 & 0] \\
\hline 0 & 0 & 0 & 28 & 0 & 0] \\
\hline 0 & 0 & 0 & 0 & 6 & 0] \\
\hline 0 & 0 & $\theta$ & 0 & 0 & 1]] \\
\hline \multicolumn{6}{|c|}{ Decision-Tree Accuracy: 0.99} \\
\hline \multicolumn{2}{|c|}{$\begin{array}{l}\text { Decision-Tree } \\
\text { Decision-Tree }\end{array}$} & \multicolumn{2}{|c|}{ Rmse: } & \multicolumn{2}{|c|}{0.021044471869825904} \\
\hline Decisi & n-Tre & $\mathrm{R}^{2}$ & & & 2138518443 \\
\hline
\end{tabular}

Şekil 17. 2020 hata matrisi (confusion matrix-2020)

\subsubsection{Naif bayes (Naive bayes-NB)}

Bayes teoreminde bulunan giriş değişkenlerinin birbirinden bağımsız olduğu bir denetimli bir makine öğrenmesi algoritmasıdır. Tahmin yapmak için her sınıfa ait her bir özelliğin olasılıklarını kullanan tahmine dayalı analiz için basit ve güçlü bir algoritmadır. NB sınıflandırıcısının oluşturulması kolaydır ve büyük veri kümeleri içinde kullanışlıdır. NB sınıflandırmasının çalışma mantığı; sisteme belirli miktarda eğitim verisi girilmesi ile başlar. Eğitim verilerinin bir sınıfa ait olması gerekmektedir. Eğitim verileri üzerinde gerçekleştirilen olasılık işlemleri ile sisteme girilen test verileri işlenir. Bu işlem daha önce elde edilen olasılık değerlerine göre yapılır ve daha sonra verilen test verilerinin sınıfı tespit edilir. Eğitim verisi sayısı ne kadar fazlaysa, test verilerinin gerçek kategorisini tespit etmek o kadar doğru olur [22]. 2019 
ve 2020 y1llarına ait veri setlerine uygulanan NB algoritması sonucunda elde edilen hata matrisleri Şekil 18 ve Şekil 19’ da verilmiştir.

\begin{tabular}{|c|c|c|c|c|}
\hline$[1151$ & 64 & 0 & 0 & 0 \\
\hline 93 & 1285 & 62 & 0 & 1 \\
\hline 0 & 5 & 182 & 3 & 0 \\
\hline 0 & 0 & 2 & 26 & 1 \\
\hline 0 & 0 & 0 & 2 & 6 \\
\hline 0 & 0 & 0 & 0 & 0 \\
\hline
\end{tabular}

Naive-Bayes Accuracy: 0.9192094313453537

Naive Bayes Rmse: 0.2890752389234825

Naive Bayes R2: 0.8150807407476385

Şekil 18. 2019 hata matrisi (confusion matrix-2019)

$$
\begin{aligned}
& \text { [6841 rows } x 6 \text { columns] }
\end{aligned}
$$

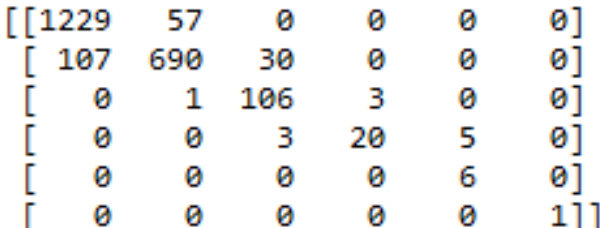

Naive-Bayes Accuracy: 0.9087688219663419

Naive Bayes Rmse: 0.3020449933928025

Naive Bayes R2: 0.8026960534799281

Şekil 19. 2020 hata matrisi (confusion matrix-2020)

\section{TARTIŞMA VE BULGULAR (DISCUSSION AND FINDINGS)}

Çalışmada verilerin \%67'si eğitim, \%33'ü test verisi olarak kullanılmıştır. Oluşturulan tahmin modeli iki veri setine de uygulanmış, modelin performans değerlendirmesinde doğruluk, RMSE ve $\mathrm{R}^{2}$ kullanılmıştır [23], [24]. Sonuçlar detaylı bir şekilde Tablo 4 ve Tablo 5 de verilmiştir.

Tablo 4. Doğruluk değerlerinin kıyaslanması2019(Comparison of accuracy values-2019)

\begin{tabular}{llllll}
\hline Yöntemler & KNN & NB & RF & DT & SVM \\
\hline Doğruluk & 0.976 & 0.919 & 0.997 & 0.999 & 0.988 \\
\hline RMSE & 0.155 & 0.289 & 0.047 & 0.016 & 0.106 \\
\hline $\mathrm{R}^{2}$ & 0.946 & 0.815 & 0.994 & 0.994 & 0.974
\end{tabular}

Çalışmada kullanılan 2019 yılı veri setine ait doğruluk değerlerinin kıyaslamasına bakıldığında en düşük RMSE(0,016) ve en yüksek doğruluk oranıyla $(\% 99,9)$ en başarılı algoritma Karar Ağacı'dır. Karar Ağacı'nı RMSE=0,047 ve \%99,7 doğruluk oranıyla Rastgele Orman algoritması takip etmektedir. En düşük başarı ise $\mathrm{RMSE}=0,289$ ve \%91,9 başarı oranıyla Naif Bayes algoritmasına aittir.
Tablo 5. Doğruluk değerlerinin kıyaslanması-2020 (Comparison of accuracy values-2020)

\begin{tabular}{llllll}
\hline Yöntemler & KNN & NB & RF & DT & SVM \\
\hline Doğruluk & 0.996 & 0.908 & 0.998 & 0.999 & 0.984 \\
\hline RMSE & 0.124 & 0.302 & 0.042 & 0.021 & 0.122 \\
\hline $\mathrm{R}^{2}$ & 0.966 & 0.802 & 0.996 & 0.999 & 0.974 \\
\hline
\end{tabular}

Çalışmada kullanılan 2020 yılı veri setine ait doğruluk değerlerinin kıyaslamasına bakıldığında yine en düsüu RMSE $(0,021)$ ve en yüksek doğruluk oranıla(\%99,9) en başarılı algoritma Karar Ağacı olmuştur. Karar Ağacı'nı sırasıyla RF, KNN, SVM, NB takip etmektedir. En başarısız algoritma ise RMSE $=0,302$ ve $\% 90,8$ başarı oranıyla Naif Bayes algoritması olmuştur.

İki farklı veri seti üzerinde makine öğrenmesi algoritmalarından KNN, SVM, RF, NB ve DT uygulanmış ve sonuçlar kıyaslandığında Karar Ağaçları ve Rastgele orman algoritmaları yüksek başarı oranına sahiptir. Literatürde yapılan çalışmalar ile oluşturulan modelin sonuçları Tablo 6'da kıyaslanmıştır.

Tablo 6. Çalışmaların doğruluk değerlerinin kıyaslanmas1 (Comparison of accuracy values of studies)

\begin{tabular}{|c|c|c|}
\hline Kaynak & Kullanılan Model & $\begin{array}{c}\text { Değerlendirme } \\
\text { Kriteri ve } \\
\text { Performans1 }\end{array}$ \\
\hline$[9]$ & $\begin{array}{c}\text { Gradient } \\
\text { Boosting } \\
\text { Regressor, RF, } \\
\text { KNN, DT }\end{array}$ & $\begin{array}{c}\text { GBR }_{\text {RMSE }}=0,9336 \\
\text { GBR }_{\text {R2 }}=0,1302\end{array}$ \\
\hline$[10]$ & DT & DT $_{\text {Doğruluk }}=\% 89,46$ \\
\hline$[11]$ & YSA, SVM & $\begin{array}{c}\text { YSAMAE }=0,0191 \\
\text { SVMAE }=0,0314\end{array}$ \\
\hline$[13]$ & RF, NB, SVM & RF $_{\text {Doğruluk }}=\% 99,1$ \\
\hline Çalışmada & $\begin{array}{c}\text { KNN, NB, RF, } \\
\text { DT, SVM }\end{array}$ & DT $_{\text {Doğruluk }=\% 99,9}$ \\
\hline
\end{tabular}

Tablo 6 incelendiğinde Karar Ağacı ve Rastgele Orman ile gerçekleştirilen modellerin diğer modellere göre daha başarılı sonuçlar ortaya koyduğu görülmektedir.

\section{SONUÇ (RESULTS)}

Hava kirliliği akciğer kanseri, astım, solunum yetmezliği gibi birçok hastalığın yayılmasında önemli bir çevresel risk faktörüdür. Günümüzde devam eden salgın sürecinde hava kalitesinin tahmin edilmesi ve buna yönelik tedbirlerin alınması hastalıkların yayılma hızını etkilemesi açısından önem taşımaktadır. Bu çalışma, geçmiş hava kalitesi verileri ve Covid-19 salgın sürecindeki günlerde ölçümlenen

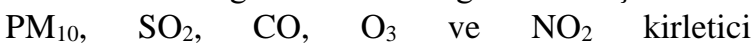


konsantrasyonlarını ele almış ve başarılı bir tahmin için hava kalitesini makine öğrenme modelleriyle analiz etmiştir. Uygulanan algoritmalar arasında 0,289(2020 veri seti) ve 0,302(2020 veri seti) RMSE değerleri ile başarısı en düşük olan Naive Bayes algoritmasıdır. En yüksek başarı 0,016(2019 veri seti) ve 0,021(2020 veri seti) RMSE değeriyle Karar Ağac1 algoritmasında elde edilmiştir.

Tüm dünyada hava kirleticilere uzun süre maruz kalma solunum yolu hastalıklarında olduğu gibi Covid-19 virüsünün yayılmasında ve ölümle sonuçlanmasında önemli bir etken olarak karşımıza çıkmaktadır. Hava kalitesinin doğru tahmini ve iyileştirilmesi salgın sürecinin uzamamasında ve hastalığ 1 hafif geçirmede önemli bir rol oynayabileceği üzerinde durulmuştur. Bütün dünya ülkeleri için Covid-19 salgını, kriz anında ve sonrasında insan sağlığını korumak adına yeniden hava kirliliği ile mücadelenin gözden geçirilmesinin önemini ortaya çıkarmıştır.

\section{TEŞEKKÜR (ACKNOWLEDGMENT)}

$\mathrm{Bu}$ çalışma, Türkiye Bilimsel ve Teknolojik Araştırma Kurumu (TÜBİTAK) 2210-A Yurt İçi Genel Yüksek Lisans Burs Programı kapsamında desteklenmiştir.

\section{ÇIKAR ÇATIŞMASI BILDİIIMI (CONFLICT OF INTEREST STATEMENT)}

Yazarlar tarafindan herhangi bir çıkar çatışması bildirilmemiştir.

\section{KAYNAKLAR (REFERENCES)}

[1] İ. Atacak, N. Arıc1, and D. Güner, "Modelling and evaluating air quality with fuzzy logic algorithmAnkara- Cebeci sample", Int. J. Intell. Syst. Appl. Eng., vol. 5, no. 4, pp. 263-268, 2018.

doi: $10.1039 / \mathrm{b} 000000 \mathrm{x}$.

[2] P. Samani, C. García-Velásquez, P. Fleury, ve Y. Van Der Meer, "The impact of the covid-19 outbreak on climate change and air quality: four country case studies", Glob. Sustain., vol. 4, pp. 1-43, Oca. 2021. doi: $10.1017 /$ sus.2021.4.

[3] T. Şimşek ve V. Yılmaz, "Hava kalitesi ile covid19 arasındaki ilişki: G-7 ülkeleri üzerine bir uygulama", J. Turkish Stud., vol. 15, no. 4, pp. 13531366, 2020. doi: 10.7827/turkishstudies.43883.
[4] E. Conticini, B. Frediani, ve D. Caro, "Can atmospheric pollution be considered a co-factor in extremely high level of SARS-CoV-2 lethality in northern Italy?", Environ. Pollut., vol. 261, no. 114465, 2020. doi: 10.1016/j.envpol.2020.114465.

[5] Zonguldak Çevre ve Şehircilik İl Müdürlüğü, “Zonguldak ili 2018 yılı çevre durum raporu”, 2019. [Çevrimiçi]. Available at: https://webdosya.csb.gov.tr/db/ced/icerikler/zonguda k_2018-cdr_son-20190926093732.pdf. [Accessed: Jun. 12, 2021]

[6] Y. Zhu, J. Xie, F. Huang, ve L. Cao, “Association between short-term exposure to air pollution and covid-19 infection: evidence from China", Sci. Total Environ., vol. 727, no. 138704, 2020. doi: 10.1016/j.scitotenv.2020.138704.

[7] D. Rodríguez-Urrego ve L. Rodríguez-Urrego, "Air quality during the covid-19: PM2.5 analysis in the 50 most polluted capital cities in the world", Environmental Pollution, vol. 266. Elsevier Ltd, Kas. 01, 2020. doi: 10.1016/j.envpol.2020.115042.

[8] E. B. Brandt, A. F. Beck, ve T. B. Mersha, "Air pollution, racial disparities, and covid-19 mortality", Journal of Allergy and Clinical Immunology, vol. 146, no. $1, \quad$ pp. 61-63, 2020. doi: 10.1016/j.jaci.2020.04.035.

[9] H. Doreswamy, K. Harishkumar, Y. Km, ve İ. M. Gad, "Forecasting air pollution particulate matter (PM2.5) using machine learning regression models", Procedia Computer Science, vol. 171, pp. 2057-2066, 2020. doi: 10.1016/j.procs.2020.04.221.

[10] G. K. Kang, J. Z. Gao, S. Chiao, S. Lu, ve G. Xie, "Air quality prediction: big data and machine learning approaches", Int. J. Environ. Sci. Dev., vol. 9, no. 1, pp. 8-16, 2018. doi: 10.18178/ijesd.2018.9.1.1066.

[11] A. Masood ve K. Ahmad, "A model for particulate matter (PM2.5) prediction for Delhi based on machine learning approaches", Procedia Computer Science, vol. 167, pp. 2101-2110, 2020. doi: 10.1016/j.procs.2020.03.258.

[12] J. K. Deters, R. Zalakeviciute, M. Gonzalez, ve Y. Rybarczyk, "Modeling PM2.5 urban pollution using machine learning and selected meteorological parameters", J. Electr. Comput. Eng., pp. 1-14, Haz. 2017. doi: 10.1155/2017/5106045. 
[13] S. Bali ve M. N. Sengar, "Indian air quality prediction and analysis using machine learning", $J$. Eng. Sci., vol. 11, no. 5, pp. 554-557, 2020.

[14] Y. Yıldırım, Ö. Zeydan, ve E. Karakavuz, "Kentleşme ve hava kalitesi açısından ilimiz Zonguldak", Zonguldak Kent Sempozyumu, ss. 8189, 2011.

[15] Zonguldak Çevre ve Şehircilik İl Müdürlüğü, "Zonguldak 2019 y1lı çevre durum raporu", 2020. [Çevrimiçi]. Available at: https://webdosya.csb.gov.tr/db/ced/icerikler/2019_zo nguldak cdr-20200914150210.pdf [Erişim tarihi: May. 21, 2021].

[16] Çevre ve Şehircilik Bakanlığı(ÇŞB), "Hava kalitesi istasyon veri indirme T.C. çevre ve şehircilik bakanlığı", 2021.

[Çevrimiçi].https://sim.csb.gov.tr/STN/STN_Report/ StationDataDownloadNew [Erişim tarihi: Mar. 10, 2021).

[17] DSÖ, "Science in 5 - episode 9 - hava kirliliği ve covid-19", 2021. [Çevrimiçi]. Avaliable:

https://www.who.int/emergencies/diseases/novelcoronavirus-2019/media-resources/science-in-

5/episode-9---air-pollution-covid-19 [Accessed: Jan. 01, 2021].

[18] DSÖ, "Koronavirüs hastalığı (covid-19): iklim değişikliğii”, $2021 . \quad$ [Çevrimiçi]. https://www.who.int/news-room/q-adetail/coronavirus-disease-covid-19-climate-change [Erişism tarihi: Ocak 01, 2021].

[19] A. Masih, "Machine learning algorithms in air quality modeling", Glob. J. Environ. Sci. Manag., vol. 5, no. 4, pp. 515-534, 2019. doi: 10.22034/gjesm.2019.04.10.

[20] J. Huo, T. Shi, ve J. Chang, "Comparison of random forest and SVM for electrical short-term load forecast with different data sources", in 7th IEEE International Conference on Software Engineering and Service Science, Beijing,China, Jul. 2016, pp. 1077-1080.

doi: 10.1109/ICSESS.2016.7883252.

[21] Z. Yao ve W. L. Ruzzo, “A regression-based k nearest neighbor algorithm for gene function prediction from heterogenous data", $B M C$ Bioinformatics, vol. 7, no. 1, pp. 1-11, Mar. 2006. doi: 10.1186/1471-2105-7-s1-s11.
[22] A. Dey, "Machine learning algorithms: a review", Int. J. Comput. Sci. Inf. Technol., vol. 7, no. 3, pp. 1174-1179, 2016.

[23] S. Çinaroğlu, "Sağlık harcamasının tahmininde makine öğrenmesi regresyon yöntemlerinin karşılaştırılması", Uludağ Üniversitesi Mühendislik Fakültesi Derg., c. 22, say1 2, ss. 179-199, 2017. doi: 10.17482/uumfd.338805.

[24] S. Karasu, A. Altan, Z. Sarac, ve R. Hacioglu, "Prediction of bitcoin prices with machine learning methods using time series data", in 26th IEEE Signal Processing and Communications Applications Conference (SIU), Izmir, Turkey, Jul. 2018, pp. 1-4. doi: 10.1109/SIU.2018.8404760.

This is an open access article under the CC-BY license (https://creativecommons.org/licenses/by/4.0/)

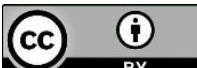

